$$
\begin{aligned}
& \text { د راسـة تشريح أوتسار أندغـام العضـلات }
\end{aligned}
$$

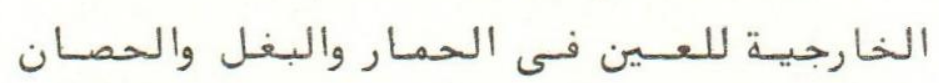

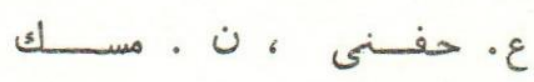

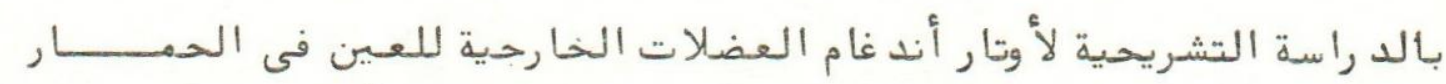

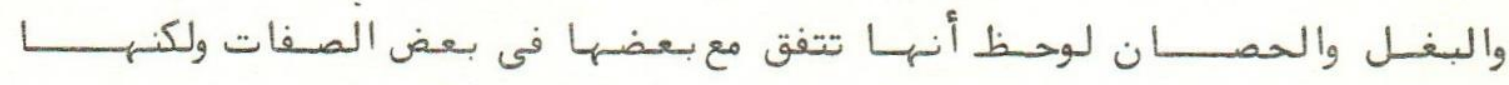

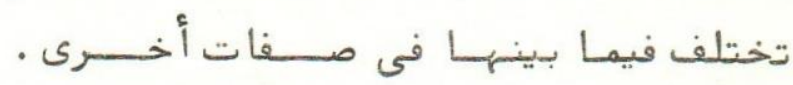

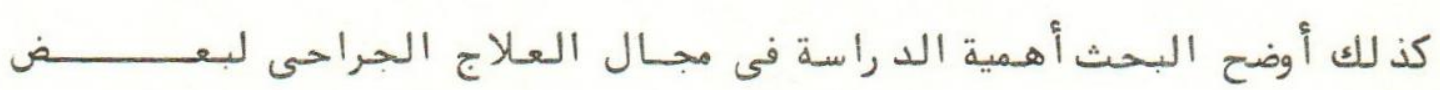

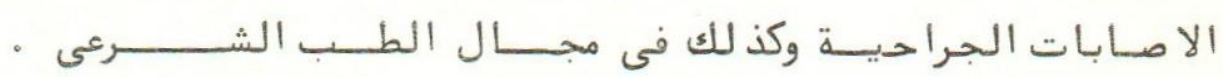




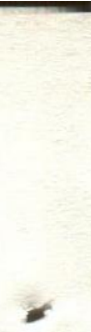

$>$

4 
Dept. of Anatomy and Surgery,

Faculty of Vet. Med. Assiut iniversity,

Head of Depts. Prof. Dr H.M. Badawi \& Prof. Dr. M. El-M. Monzaly.

\title{
THE ANATOMY OF THE TENDONS OF INSERTION OF THE EXTRINSIC MUSCLES OF THE EYEBALL IN THE DONKEY, MULE AND HORSE (With 3 Tables and 3 Figures)
}

By

A. HIFNY and N.A. MISK

(Received at 15/2/1979)

\begin{abstract}
SUMMARY
The knowledge of the insertion of the eyeball's extrinsic muscles is of an importance in the surgery and in the forensic medicine.

The insertion of the extrinsic muscles of the eyeball. in horses can be differentiated from that of mules and donkeys as regards the line of insertion of the dorsal oblique and the mode of insertion of the ventral oblique muscle. Also the eyeball in equine can be differetiated easily from that of large ruminants, by many several features concerning the insertion of the dorsal, medial and lateral, rectus. The position of the tendon of insertion of the ventral rectus and the charater of ventral oblique muscle insertion into the sclera.
\end{abstract}

\section{INTRODUCTION}

The straight and oblique extrinsic muscles of the eyeball in donkey, mule and horse are not inserted at equal distances from the corneoscleral junction like that in other domestic animals ( HIFNY, 1977 and MISK, 1978 ).

The study of the insertion of the ocular muscles is of an importance for the treatment of some surgical affections such as strabismus which necessitates the recession or resection of one or more of the muscles, suppurative endophthalmitis which needs enucleation of the eyeball by severing the tendons of insertion of the extraocular muscles and in other instances in which one may need to know accurately the length, direction, distance of the line of insertion of each muscle from the

Assiut Vet.Med.J.Vol. 7, No. 13\&14,1980. 
HIFNY and MISK

limbus and the length of its tendinous part. The anatamical study of the ocular muscles is an aid in forensic medicine.

\section{MATERIALS AND METHODS}

The tendons of insertion of the extrinsic muscles of the eyeball were studied in horses, mules and donkeys. Twenty eyes (10 left and 10 right) of donkeys and ten eyes (5 left and 5 right) of mules and horses were obtained from a newly sacrified animals. Each extraocular muscle was examined fully including the length, breadth and direction of its tendinous part, and distance of its line of insertion from the limbus.

For the muscles having a curved or oblique line of insertion more than one reading was taken to identify more accurately the distance of this line from the limbus. The horizontal and vertical diameters of the cornea were measured to show the relative size of the eyeball on which the extrinsic muscles were studied.

The measurements were not made on animals of specific sexes and breeds. The average of the readings of different measurements in each species was obtained.

\section{RESULTS}

Donkey: (Fig. 1 and Table 1):

The dorsal rectus muscle can be distinguished by having the longest tendon of insertion while that of the ventral rectus is the shortest tendon of insertion of any of the extraocular muscles. The tendon of the ventral rectus muscle is completely situated medial to the vertical plane of the cornea. The line of insertion of the dorsal rectus is irregular, of the ventral rectus is straight, of the lateral rectus is slightly concave, of the medial rectus is strongly convex, of the dorsal oblique is straight and of the ventral oblique is strongly convex towards the cornea. The line of insertion of the dorsal oblique is directed almostly backward. The medial end of this line is covered by the lateral border of the tendon of insertion of the dorsal rectus, while the lateral end is situated between and behind the lines of insertion of the dorsal

Assiut Vet.Med.J.Vol. 7, No. 13\&14,1980. 


\section{EXTRINSIC MUISCLES OF THE EYEBALLS}

rectus muscles. The insertion of the ventral oblique is almost completely muscular. The retractor bulbi lies within the recti and behind them and its insertion is almost entirely muscular.

Mule: (Fig. 2 and Table 2):

The dorsal rectus muscle has the widest tendon and the ventral has the narrowest tendon of insertion of any of the extraocular muscles. The line of insertion of the dorsal rectus is irregulur, the ventral rectus is straight, the lateral rectus is slightly concave, the medial rectus is strongly convex, the dorsal oblique is straight, and the ventral oblique is strongly convex towards the cornea. The line of insertion of the dorsal oblique is directed almostly backward. The near end lies under the lateral border of the tendon of insertion of the dorsal rectus and the far end is situated between and behind the lines of insertion of insertion of the dorsal and lateral recti. The insertion of the ventral oblique is completely muscular and situated between the tendons of insertion of the ventral and lateral rectus muscles. The lateral border of the muscle is connected by some muscular fibers with the retractor bulbi.

Horse (Fig. 3 and Table 3):

The line of insertion of the dorsal rectus is irregular, the ventral rectus is straight, the lateral rectus is slightly concave and the medial rectus is strongly convex toward the cornea. The tendon of insertion of the ventral rectus is completely situated medial to the vertical plane of the cornea. The line of insertion of the dorsal oblique is directed almostly laterally. The near end of the later lies under the lateral border of the tendon of insertion of the dorsal rectus, while the far end is situated between and behind the lines of insertion of the dorsal and lateral recti. The line of insertion of the ventral oblique is convex. The medial part of the insertion is tendinous while the lateral part is almost entirely muscular. The lateral border of the ventral oblique is connected by some muscular fibers with the retractor bulbi, Assiut Vet.Med.J.Vol. 7, No. 13814,1980. 


\section{HIFNY and MISK}

and also some muscular fibers of the later extend under the muscular insertion of the ventral oblique.

\section{DISCUSSION}

Some authors (SMYTHE, 1958; ARAEVSKY, 1968; BRADLEY, 1973 and GETTY, 1975) have described the insertion of the extrinsic muscles of the eyeball into the sclera in equine but without indicating the width, direction and distance of the line of insertion of these muscles from the limbus.

The description of these authors are not sufficient to satisfy the requirements needed by ophthalmogests for treatment of many surgical affections of the eyeball.

The insertions of the extrinsic ocular nuscles in large ruminants (HIFNY and MISK, 1977) can be differentiated from that of equine by several features.

The line of insertion of the dorsal rectus muscle is irregular in equine and nearly straight in large ruminants. The insertion of the medial rectus is convex in equine and straight in large ruminants. The lateral rectus is inserted into the sclera by a concave line toward the cornea in equine and by an oblique line in large ruminants.

The tendon of insertion of the ventral rectus is situated completely medial to the vertical plane of the cornea in equine but in large ruminants it is situated on the vertical plane of the cornea. The tendon of insertion of the ventral oblique is partially situated under the tendon of insertion of the lateral rectus muscle in large ruminants but in equine it is situated between the tendons of insertion of the ventral and lateral recti.

Also the insertion of the ventral oblique is completely muscular in equine except the hoose (very small part of the medial border of the insertion is tendinous), while in large ruminant the insertion is partially

Assiut Vet.Med.1.Vol. 7, No. 13814,1980. 


\section{EXTRINSIC MLISCLES OF THE EYEBALLS}

(buffaloe and camel) or completely tendinous (cattle). The lateral border of the muscular insertion of the ventral oblique muscle is connected partially by many muscular fibers with the retractor bulbi and some fibers of the later extends under the muscular insertion of the ventral oblique in equine. In large ruminants there is no connection between the ventral oblique and retractor bulbi.

From the knowledges mentioned above we can say that the eyeball in equine can be easily differentiated from that of the large ruminants. This fact is of importance for the judgement of quality of the meat when the eyeball or part of it is present in the carcus.

The eyeball in donkeys and mules cannot be easily differentiated from each other; the measurements of each tendon of insertion is the only difference between the extrinsic muscles of the eyeball in donkey and mule.

The eyeball of the horse can be differentiated by many features from that of donkey and mule.The line of insertion of the dorsal oblique muscle in the horse is directed laterally and appears to be almostly parallel to the limbus, while in the donkey and mule these lines are directed completely caudalward and appears to be perpendicular to the limbus. The insertion of the ventral oblique muscle in donkey and mule is completely muscular and in horse the medial part of this insertion is tendinous. Also the vertical and the horizontal plane of the cornea in the horse are larger than that of the mule and donkey.

Knowledge of insertion of the extraocular muscles is of importance in the treatment of many surgical affection in equine which necessitate enucleation of the eyeball. This knowledge is needed to detect accurately the methods of surgical exposure of each tendon and to ascertain the direction of the surgical tenotome.

In cases of strabismus the distance of the line of insertion from the limbus and the mode of insertion of each tendon are required to posAssiut Vet.Med.J.Vol. 7, No. 13\&14,1980. 
HIFNY and MISK

tulate the method of exposure of each tendon and to know whother this condition can be corrected by recession, ressection, advancement, tucking or by marginal tenotomy. Also the obtained results show that the most preferable method for lens extraction in cases of cataract and cyclodialysis in cases of glaucoma is at the medial and dorsal parts of the limbus. These positions are apart form the lines of insertions of the dorsal rectus, dorsal oblique and medial rectus muscles. Operation which are carried on the lateral and ventral parts of the limbus may expose the insertions of the lateral and ventral rectus and ventral oblique muscles to injury as these muscles are closely inserted to the limbus.

\section{REFERENCES}

Akaevsky,A.E. (1968): The anatomy of domestic animals. Kolos,Moscow.

Bradley,O.C. (1946): Topographical anatomy of the horse, 2 Ed. W. Green and Son, limited.

Getty,R. (1975): Sisson and Grossman's Anatomy of domestic animals, 5th Ed. Saunders Co., philadelphia. London. Toronto.

Hifny,A. and Misk,N.A. (1977): The anatomy of the tendons of insertion of the extrinsic muscles of the eyeball in the Buffalo, Cow and Camal. Zbl. Vet. Med.C.;Anat. Hist Embryol. 6, 339-346.

Hifny, A. and Misk,N.A. (1977): The anatomy of the tendons of insertion of the extrinsic muscles of the eyeball in sheep and goat. Assiut Vet.Me.J.Vol. 4, No. 8, pp. 10-19.

Misk,N.A. and Hifny,A. (1978): The anatomy of the tendons of insertion of the extrinsic muscles of the eyeball in dog and cat. Egypt. J.Vet.Sci., 15, No. 1-2, pp. 55-59.

Smythe,R.H., (1958): Veterinary ophthalmology. Second edition, Bailliere Tindall, Cox Ltd and London.

Assiut Vet.Med.J.Vol. 7, No; 13\&14,1980. 


\section{EXTRINSIC MUSCLES OF THE EYEBALLS}

Table (1): Showing the distance, length and width of the tendons of insertion of the extrinsic muscles of the eyeball in the donkey. (in $\mathrm{cm}$ ).

\begin{tabular}{|c|c|c|c|c|}
\hline Tendon & Distance & from the limbus & width & Length \\
\hline \multirow[t]{2}{*}{ Dorsal } & near end & 0.80 & 2.50 & 2.00 \\
\hline & far end & 1.10 & & \\
\hline Ventral R.M. & centre & 0.78 & 1.80 & 1.05 \\
\hline \multirow[t]{2}{*}{ Lateral R.M. } & upper end & 1.25 & & \\
\hline & lower end & 0.31 & 2.30 & 1.25 \\
\hline \multirow[t]{3}{*}{ Medial R.M. } & centre & 1.40 & & \\
\hline & upper end & 2.41 & 2.70 & 1.24 \\
\hline & lower end & 1.85 & & \\
\hline \multirow[t]{2}{*}{ Dorsal O.M. } & near end & 1.47 & & \\
\hline & far end & 2.80 & 1.57 & 2.00 \\
\hline \multirow[t]{2}{*}{ Ventral O.M. } & near end & 0.30 & \multirow[b]{2}{*}{2.52} & \\
\hline & far end & 1.89 & & \\
\hline \multirow{4}{*}{$\begin{array}{l}\text { Retractor } \\
\text { bulbi }\end{array}$} & dorsally & 3.41 & \multirow{4}{*}{---- } & \multirow{4}{*}{$-\cdots$} \\
\hline & ventrally & 1.82 & & \\
\hline & laterally & 1.98 & & \\
\hline & medially & 2.26 & & \\
\hline
\end{tabular}

Assiut Vet.Med.J.Vol. 7, No. 13814,1980. 


\section{HIFNY and MISK}

Table (2): Showing the distance, length and width of the tendons of insertion of the extrinsic muscles of the eyeball in the mule. (in cm).

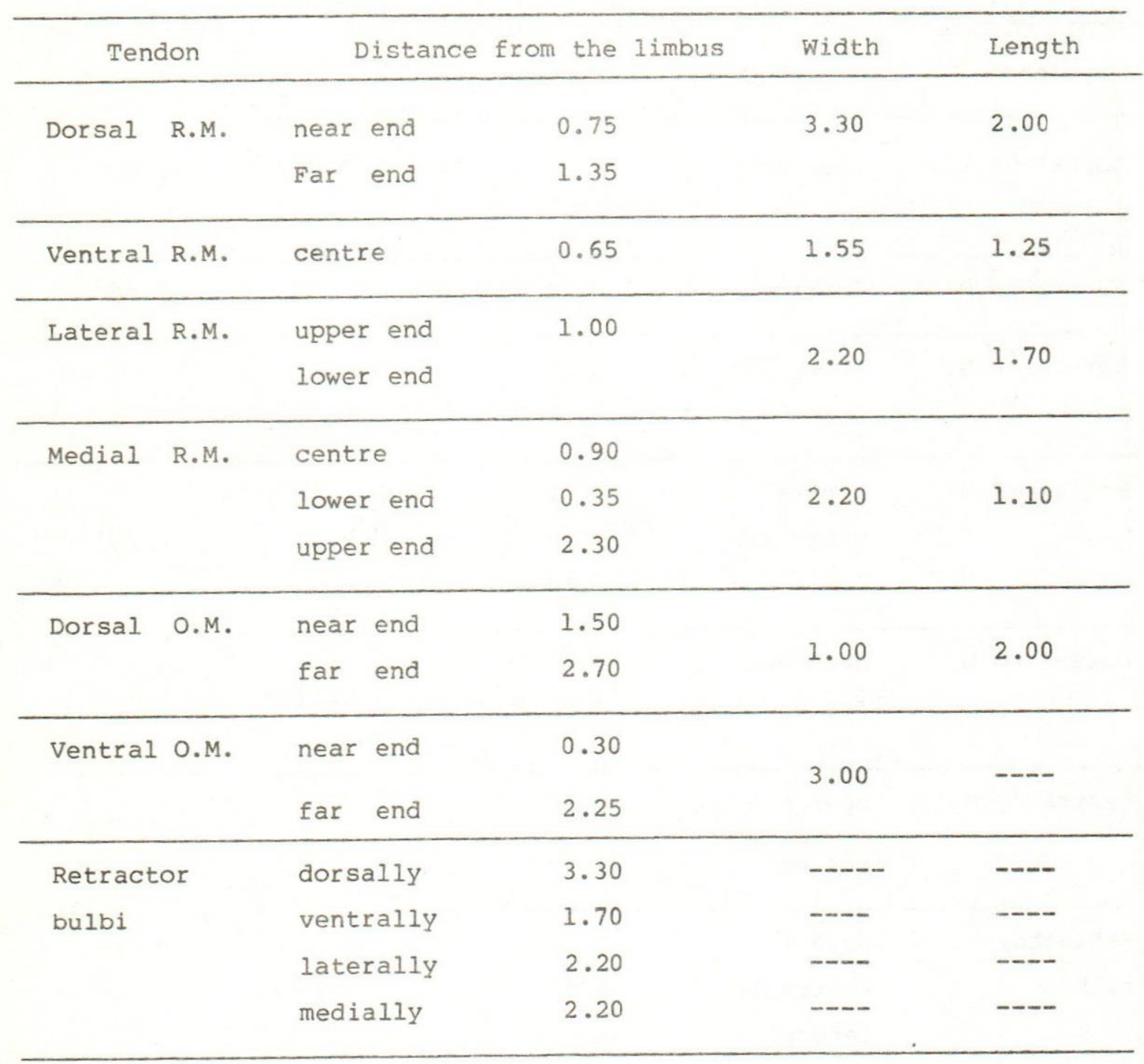

Assiut Vet.Med.J.Vol. 7, No. 13\&14,1980. 


\section{EXTRINSIC MUSCLES OF THE EYEBALLS}

Table (3): Showing the distance, length and width of the tendons of insertion of the extrinsic muscles of the eyeball in the horse. (in $\mathrm{cm}$. ).

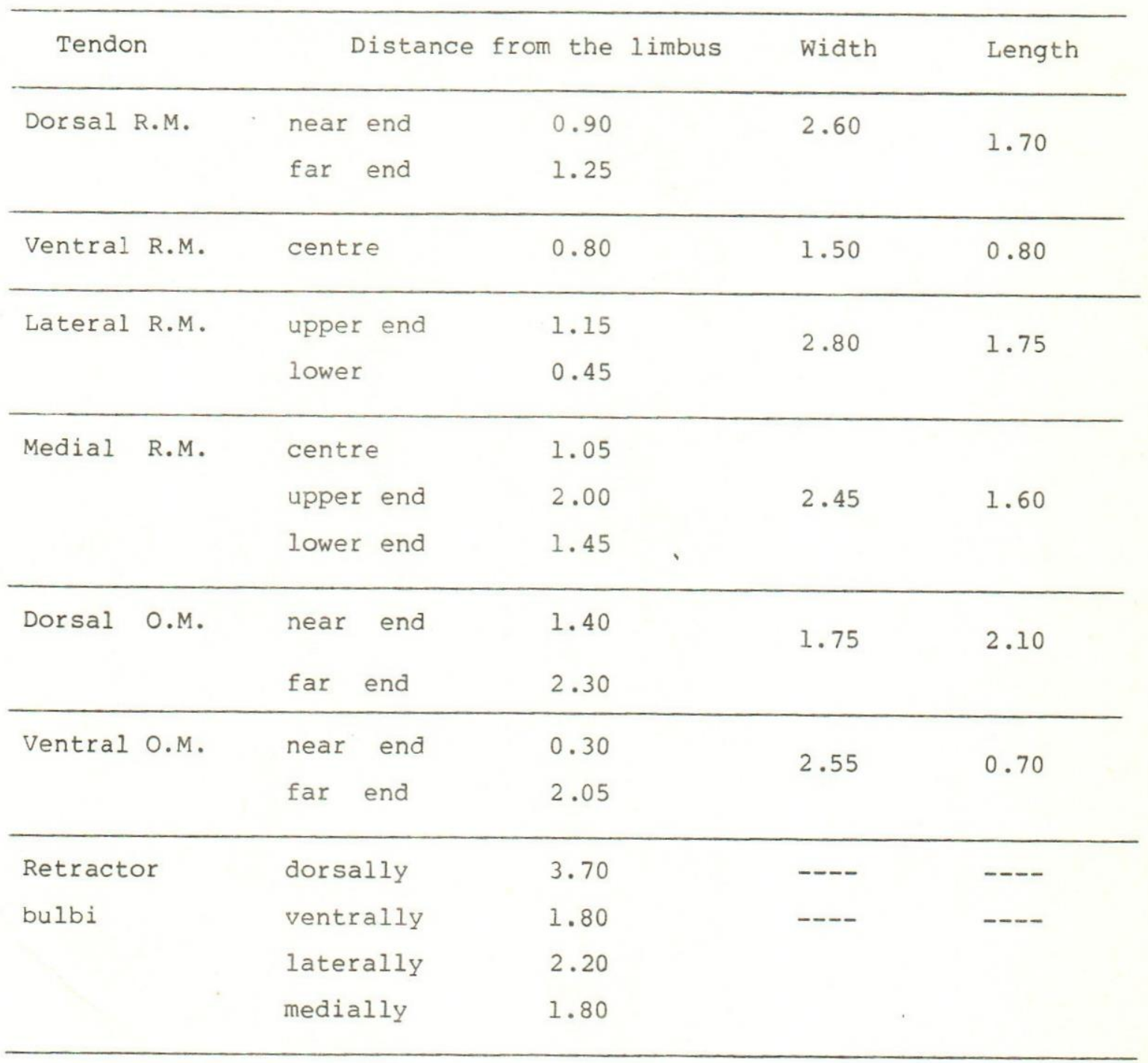

Assiut Vet.Med.J.Vol. 7, No. 13\&14,1980. 
i $=$ 
Fig. 1 : Diagram showing the site, length and width of the tendons of insertion of the extrinsic muscles of the eyeball in the donkey.

Fig. 2 : Diagram showing the site, length and width of the tendons of insertion of the extrinsic muscles of the eyeball in the mule.

Fig. 3 : Diagram showing the site, length and width of the tendons of insertion of the extrinsic muscles of the eyeball in the horse. 


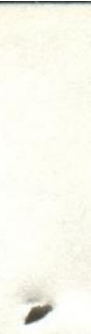

s.

is 


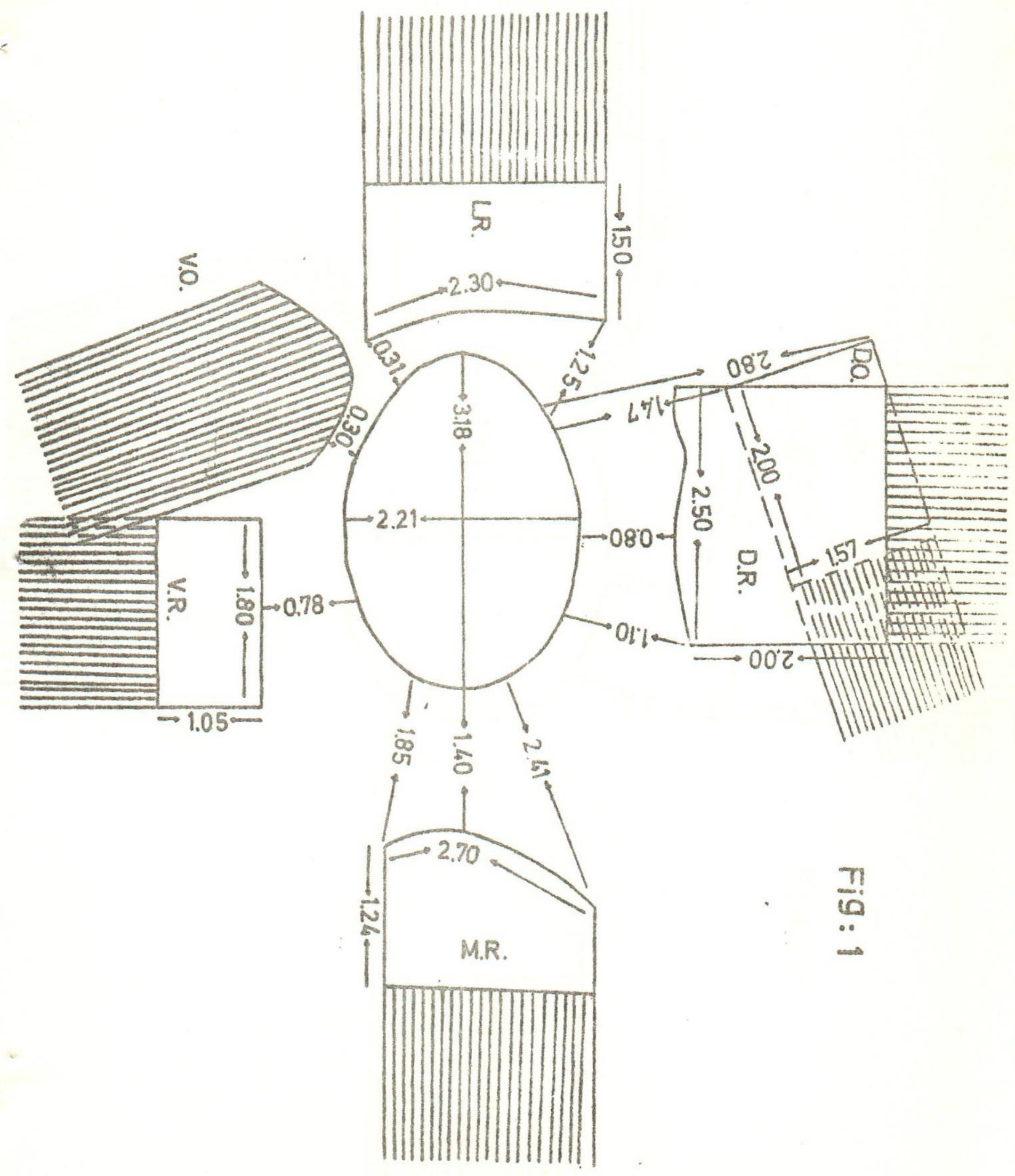




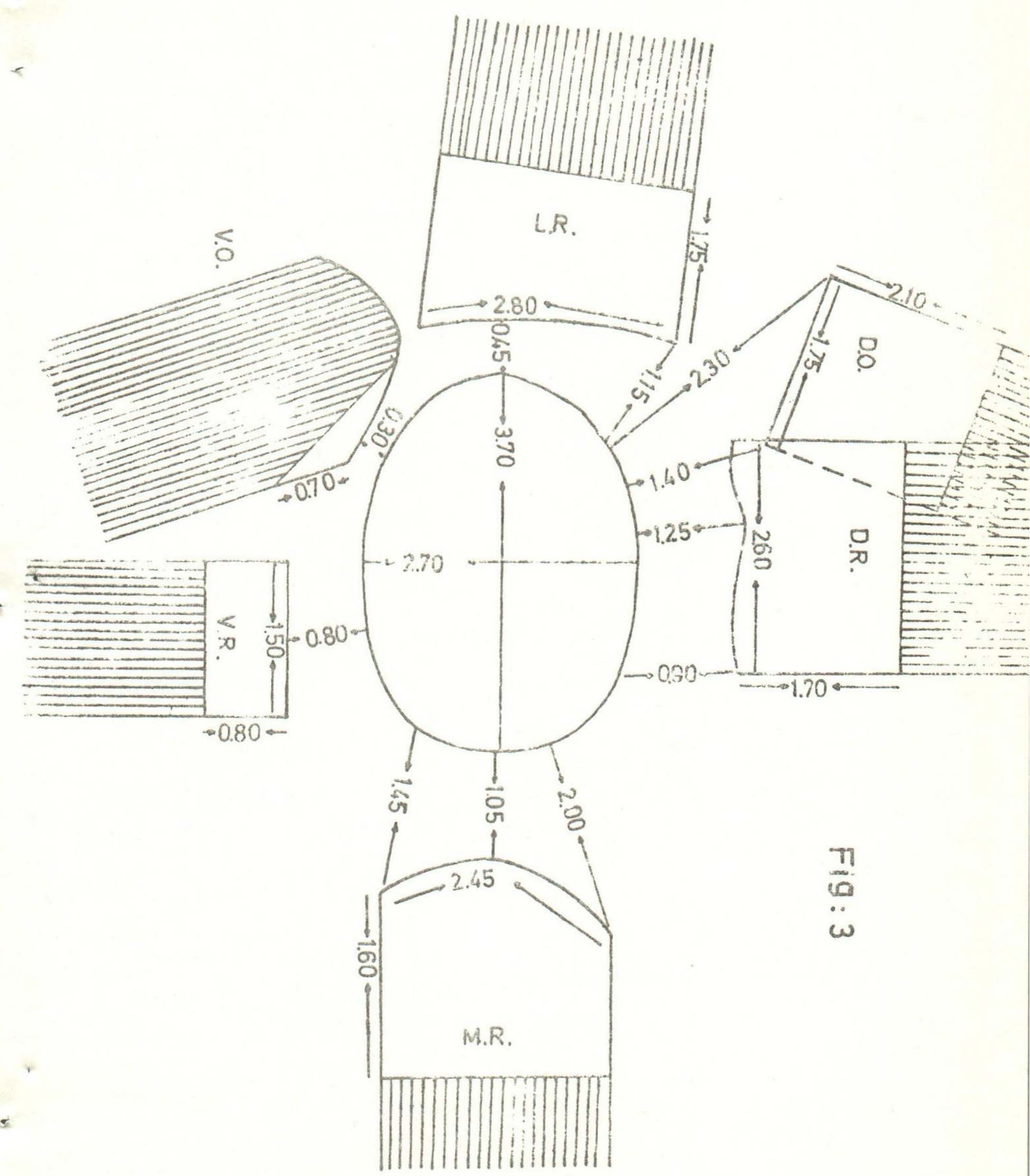




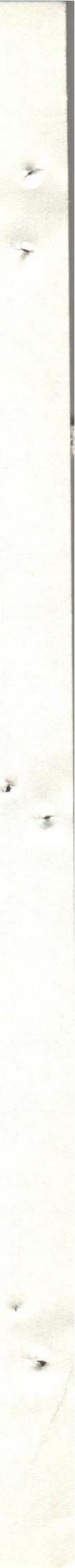

